\title{
Molecular dietary analyses of western capercaillies (Tetrao urogallus) reveal a diverse diet
}

\author{
Physilia Ying Shi Chua ${ }^{1,2}$ (1) | Youri Lammers ${ }^{3} \odot$ | Emmanuel Menoni ${ }^{4}$ | \\ Torbjørn Ekrem $^{5} \odot$ | Kristine Bohmann ${ }^{1} \odot$ | Sanne Boessenkool ${ }^{6} \odot$ | Inger Greve Alsos ${ }^{3} \odot$
}

\author{
${ }^{1}$ Section for Evolutionary Genomics, \\ Globe Institute, University of \\ Copenhagen, Copenhagen, Denmark \\ ${ }^{2}$ Department of Biology, Faculty of \\ Science, University of Copenhagen, \\ Copenhagen, Denmark \\ ${ }^{3}$ The Arctic University Museum of \\ Norway, UiT - The Arctic University of \\ Norway, Troms $\varnothing$, Norway \\ ${ }^{4}$ Office Francais de la Biodiversité \\ (French Office for Biodiversity, UPFSEO, \\ Villeneuve de Rivière, France \\ ${ }^{5}$ Department of Natural History, NTNU \\ University Museum, Norwegian University \\ of Science and Technology, Trondheim, \\ Norway \\ ${ }^{6}$ Department of Biosciences, Centre for \\ Ecological and Evolutionary Synthesis \\ (CEES), University of Oslo, Oslo, Norway
}

\section{Correspondence}

Physilia Ying Shi Chua, Section for Evolutionary Genomics, Globe Institute, University of Copenhagen, Øster

Farimagsgade 5, 1353 Copenhagen K, Denmark.

Email: physiliachua@gmail.com

Funding information

European Commission, Grant/Award Number: 765000

\begin{abstract}
Conservation strategies centered around species habitat protection rely on species' dietary information. One species at the focal point of conservation efforts is the herbivorous grouse, the western capercaillie (Tetrao urogallus), which is an indicator species for forest biodiversity conservation. Non-molecular means used to study their diet are time-consuming and at low taxonomic resolution. This delays the implementation of conservation strategies including resource protection due to uncertainty about its diet. Thus, limited knowledge on diet is hampering conservation efforts. Here, we use non-invasive environmental DNA (eDNA) metabarcoding on DNA extracted from faces to present the first large-scale molecular dietary analysis of capercaillies. Facal samples were collected from seven populations located in Norway (Finnmark, Troms, Trøndelag, Innlandet) and France (Vosges, Jura, Pyrenees) $(n=172)$. We detected 122 plant taxa belonging to 46 plant families of which $37.7 \%$ of the detected taxa could be identified at species level. The average dietary richness of each sample was $7 \pm 5 S D$ taxa. The most frequently occurring plant groups with the highest relative read abundance (RRA) were trees and dwarf shrubs, in particular, Pinus and Vaccinium myrtillus, respectively. There was a difference in dietary composition (RRA) between samples collected from the different locations (adonis pseudo $F_{5,86}=11.01, r^{2}=0.17$, $p=0.001$ ) and seasons (adonis pseudo $F_{2,03}=0.64, r^{2}=0.01, p=0.036$ ). Dietary composition also differed between sexes at each location (adonis pseudo $F_{1,47}=2.77, r^{2}=$ $0.04, p=0.024)$, although not significant for all data combined. In total, 35 taxa (36.8\% of taxa recorded) were new capercaillie food items compared with existing knowledge from non-molecular means. The non-invasive molecular dietary analysis applied in this study provides new ecological information of capercaillies' diet, improving our understanding of adequate habitat required for their conservation.
\end{abstract}

\section{KEYWORDS}

ecology, environmental DNA, grouse, herbivory, high-throughput sequencing 


\section{1 | INTRODUCTION}

Over the past few centuries, anthropogenic actions such as urbanization, habitat fragmentation, over-harvesting, and introduction of invasive species have accelerated the loss of biodiversity worldwide (Ceballos et al., 2010). Based on the latest report from the Intergovernmental Science-Policy Platform on Biodiversity and Ecosystem Services, more than 1,000,000 species are currently threatened with extinction (IPBES, 2019). Hence, there is a critical need to obtain ecological data, which can be used to alleviate the decline of species through conservation strategies (Ceballos et al., 2015; Cracraft, 1995). To formulate effective conservation strategies, reconstruction of animal diet plays an important role in understanding species interactions, ecosystem functions, and habitat selection (Clare, 2014; Kunz et al., 2011). As diet is intrinsically linked to habitat selection, diet information is a key element used for planning appropriate habitat protection strategies (González et al., 2012), and for managing habitat restoration projects (Iwanowicz et al., 2016). In herbivores, diet studies have been widely applied in ecological studies including temporal variability in diet compositions (Aziz et al., 2017; Rayé et al., 2011), foraging plasticity (Kowalczyk et al., 2019; Quéméré et al., 2013), resource competition and niche partitioning (Kartzinel et al., 2015; Lopes et al., 2015; ter Schure et al., 2020; Soininen et al., 2015), impacts of herbivores on vegetation (Bilodeau et al., 2014; Hibert et al., 2011), and diet authentication of grazing livestock (Pegard et al., 2009).

The herbivorous grouse species, the western capercaillie (Tetrao urogallus), has been the focus of conservation efforts centered around boreal forest habitat protection and restoration (Storch, 2007). Due to its strong association with mature old-growth forests and its relatively large home range, the western capercaillie is also an indicator species for forest biodiversity conservation (Suter et al., 2002). Capercaillies are widely distributed across the boreal and montane forests in Eurasia, but these birds are particularly susceptible to anthropogenic disturbances, including land-use change, habitat destruction, and forest management practices (Klaus \& Bergmann, 1994; Storch, 2007). As a result, populations in Central and Western Europe are fragmented due to habitat loss and uneven distribution patterns of conifer forests, and local extinctions have been recorded in the French Alps and Britain (Duriez et al., 2007; Storch, 2000). Capercaillies are now listed in Annex I of the Birds Directive in European countries, where suitable habitats must be protected to ensure their survivability. To obtain a complete understanding of the capercaillie habitat, detailed knowledge of its diet and how this varies throughout the species' range is a crucial step for conservation management.

Capercaillies are mainly folivores, and they spend a considerable amount of time foraging due to low intake rate (Blanco-Fontao et al., 2010; Sedinger, 1997). Specialization on food resources depends on local conditions, where only a few plants are important diet items throughout the capercaillies' range (Sedinger, 1997). Traditionally, capercaillie diet studies were based on direct observations during foraging events (Gustafsson, 2008), but capercaillies are highly susceptible to human disturbances making direct observations challenging and detrimental to their well-being (Duriez et al., 2007; Mikoláš et al., 2015). Another method commonly used is the microhistological identification of plants through analysis of crop contents (Borchtchevski, 2009; Wegge \& Kastdalen, 2008). This method is invasive, requiring capercaillies to be hunted and killed. Other noninvasive means have also been employed such as browsing signs analysis (Gustafsson, 2008) and microhistological identification of ingested plants in their fecal samples (Blanco-Fontao et al., 2010; González et al., 2012; Odden et al., 2003; Picozzi et al., 1996, 1999; Rodrìguez \& Obeso, 2000). However, these non-molecular methods are extremely time-consuming, requiring trained researchers to accurately identify their diet, and identifications are prone to errors or observer bias (Sheppard \& Harwood, 2005). Easily digested plants often go undetected, and detected plants are often identified at a low taxonomic resolution (Shrestha \& Wegge, 2006). The diet identified using such methods is therefore typically described using only common names such as ferns, grasses, heaths, and mosses, without species or even genus-specific resolution (Blanco-Fontao et al., 2010; González et al., 2012; Odden et al., 2003). With the advent of high-throughput sequencing (HTS) technologies such as DNA metabarcoding, an alternative non-invasive means of studying their diet through fecal samples is possible (Valentini et al., 2009a). This reduces the effect of human disturbances on the capercaillies as fecal samples can be readily collected after key foraging periods, to decrease the risk of flight or altered behavior (Thiel et al., 2008).

DNA metabarcoding of fecal samples to characterize diet has been used in many herbivore diet studies (Erickson et al., 2017; Iwanowicz et al., 2016; Kowalczyk et al., 2019; Soininen et al., 2015; Valentini et al., 2009a). It is a HTS technique that amplifies taxonomically informative genetic regions in complex or environmental samples such as feces, by targeted PCR amplification using generic primers (Valentini et al., 2009a). Metabarcoding allows for large-scale parallel sequencing of samples from many individuals (Valentini et al., 2009a), which is cost-effective and allows for population-scale diet studies (Quéméré et al., 2013). Compared with traditional methods, metabarcoding can give better taxonomic resolution and identify a wider breadth of diet items provided that a well-populated species reference database is available (Soininen et al., 2009; Srivathsan et al., 2016; Valentini et al., 2009b). Metabarcoding can also be used to reconstruct diet in degraded fecal samples not collected immediately after defecation (Chua et al., 2021; Hawlitschek et al., 2018). Such flexibility is advantageous when studying the diet of elusive animals like the capercaillies, where care should be taken not to disturb them, particularly during foraging periods and the breeding season.

Currently, only two studies have used metabarcoding to reconstruct the diet of capercaillies, and both studies included less than ten individuals each (Chua et al., 2021; Valentini et al., 2009a). As such, the potential for large-scale metabarcoding analysis of capercaillie diet to retrieve a wider breadth of diet items has not been explored. Strategies focusing on the protection of food resources could be delayed due to uncertainty about its diet, and which are the most important diet items to conserve. By addressing dietary 
variation within and among populations, we can better tailor conservation efforts to ensure the survival of the capercaillies. Here, we present the first large-scale metabarcoding diet analysis of the western capercaillies and by doing so, we can obtain more detailed diet information across the different spatial and temporal scales. We aim to (1) document the dietary richness and composition of the plants consumed by capercaillies, (2) explore diet variation between capercaillie populations across Norway and France, (3) explore the diet variation between sexes and seasons, and 4) assess whether metabarcoding retrieves any new plant diet items as compared to previously recorded plant diet items obtained through traditional non-molecular methods. To achieve these aims, we carry out metabarcoding of western capercaillie fecal droppings collected in spring and autumn from populations in seven different locations across Norway and France (Norway: Finnmark, Troms, Trøndelag, Innlandet. France: Vosges, Jura, Pyrenees). These populations are representative of the three major geographical regions inhabited by the capercaillies; Northern Europe (Norway), Central Europe (Vosges and Jura), and Southern Europe (Pyrenees, one of the southernmost capercaillie populations in the world). Hence, this study could reveal insights into the capercaillie's diet across its geographical range.

\section{2 | MATERIALS AND METHODS}

\section{1 | Study sites and fecal collection}

In Norway, capercaillies are classified as Least Concerned (LC) and can be found in the boreal forests across most of the country (https:// www.biodiversity.no/). The study areas are mostly dominated by pine (Pinus sylvestris), spruce (Picea abies), birch (Betula pubescens), aspen (Populus tremula), and ericaceous dwarf shrubs (Vaccinium spp) (Wegge \& Kastdalen, 2008). The estimated population size is around 25,000 to 30,000 individuals (http://www.birdlife.org). In France, capercaillies are highly threatened and mostly restricted to the Vosges, Jura, and Pyrenees mountains, with an estimated population size of less than 50, 300, and 4000 individuals, respectively (http:// www.birdlife.org; Observatoire des Galliformes de Montagne, 2020; Parc Naturel des Ballons des Vosges, 2019). They are classified as vulnerable (VU) in Pyrenees, and endangered (EN) in both Vosges and Jura (https://uicn.fr/listes-rouges-regionales/). The study area in Vosges and Jura is dominated by spruce (Picea abies), fir (Abies alba) and beech (Fagus sylvatica). For Vosges, there is a fairly good diversity of both coniferous and deciduous trees on the edges of clearings, and peat bogs can be found in the forests. Depending on the soil and forest cover, rich herbaceous vegetation or ericaceous field layer is present. For Jura, higher elevation parts are dominated by subalpine mountain pine woods (Pinus uncinata) with rich herbaceous vegetation on limestones. However, ericaceous plants are locally present on decarbonized humus. In the Pyrenees, the mountain forests are strongly dominated by fir (Abies alba), beech (Fagus sylvatica) or pine (Pinus uncinata). Near the tree line, there is a rich mixture of different species of trees such as rowan (Sorbus aucuparia) and birch (Betula verrucosa), shrublands dominated by rhododendron (Rhododendron ferrugineum), and a variety of herbaceous plants. On one of these mountains, two non-native species of trees in the Pyrenees have been planted in the 19th century in small patches: (Spruce (Picea abies) and larch (Larix decidua)). The estimated coverage of main plant taxa found at each site can be found in more details in Appendix S1: Table S1.

For our study, we collected a total of 232 fecal samples from western capercaillies in both Norway and France (Appendix S1: Table S2). In Norway, 164 samples were collected between 2018 and 2019, during autumn (September to November) and spring (April to June). Collections in Norway were carried out in the following counties; Finnmark (6 samples), Innlandet (106 samples), Troms (23 samples), and Trøndelag (56 samples). In France, 68 samples were collected in spring (April to June) between 2016 and 2019, from the following mountain ranges; Jura (18 samples), Vosges (30 samples), and Pyrenees (Ariège and Haute-Garonne) (20 samples) (Figure 1). The estimated sampling coverage of our dataset was calculated based on the number of samples collected within the sampling sites, over the total estimated population size in each of these areas. The sampling coverage for the Norwegian population was estimated to be around $0.7 \%$, whereas it was around $1.6 \%$ for the French population.

Each fecal sample corresponds to one dropping deposited by one individual. Faucal samples were collected in sterile airtight tubes containing Merck silica gel (with color indicator, granulate size 1-3 $\mathrm{mm}$, Merck $\mathrm{KGaA}$ ). To minimize the chance of collecting multiple samples from the same individual, only fecal droppings that were minimum $25 \mathrm{~m}$ apart were collected (Mollet et al., 2015). All fecal samples were collected opportunistically in the field except one sample, Z01, which was collected from a captive male capercaillie located at the Namsskogan Familiepark (Trøndelag, Norway). For each fecal dropping sample, the sex of the capercaillies who deposited the samples was determined by either visual observation of the defecating individual if present, or by measuring the diameter of the fecal samples (>10 $\mathrm{mm}$ for males, $<8 \mathrm{~mm}$ for females). The relationship between dropping diameter and sex of capercaillies have been validated through observation or genotyping (Moss et al., 2014; Thiel et al., 2008; Vallant et al., 2018). The fecal samples were stored at $-20^{\circ} \mathrm{C}$ prior to DNA extraction.

\subsection{DNA extraction and metabarcoding}

DNA extractions were carried out in a dedicated pre-PCR laboratory. For each fecal dropping, approximately $2 \mathrm{~mm}$ of the exterior layers of each faces were removed to reduce environmental contamination. For DNA extraction, approximately $200 \mathrm{mg}$ of fecal material was used for each sample. DNA extractions were carried out following the QIAGEN PowerFaecal DNA Isolation Kit using the manufacturer's protocol (QIAamp PowerFecal DNA Kit Handbook 08/2017), with the following modification: DNA was eluted in 100 $\mu \mathrm{l}$ Solution $\mathrm{C} 6$ with an incubation time of $15 \mathrm{~min}$ at $37^{\circ} \mathrm{C}$ to increase DNA yield. DNA extractions were carried out in batches of 25 to 40 


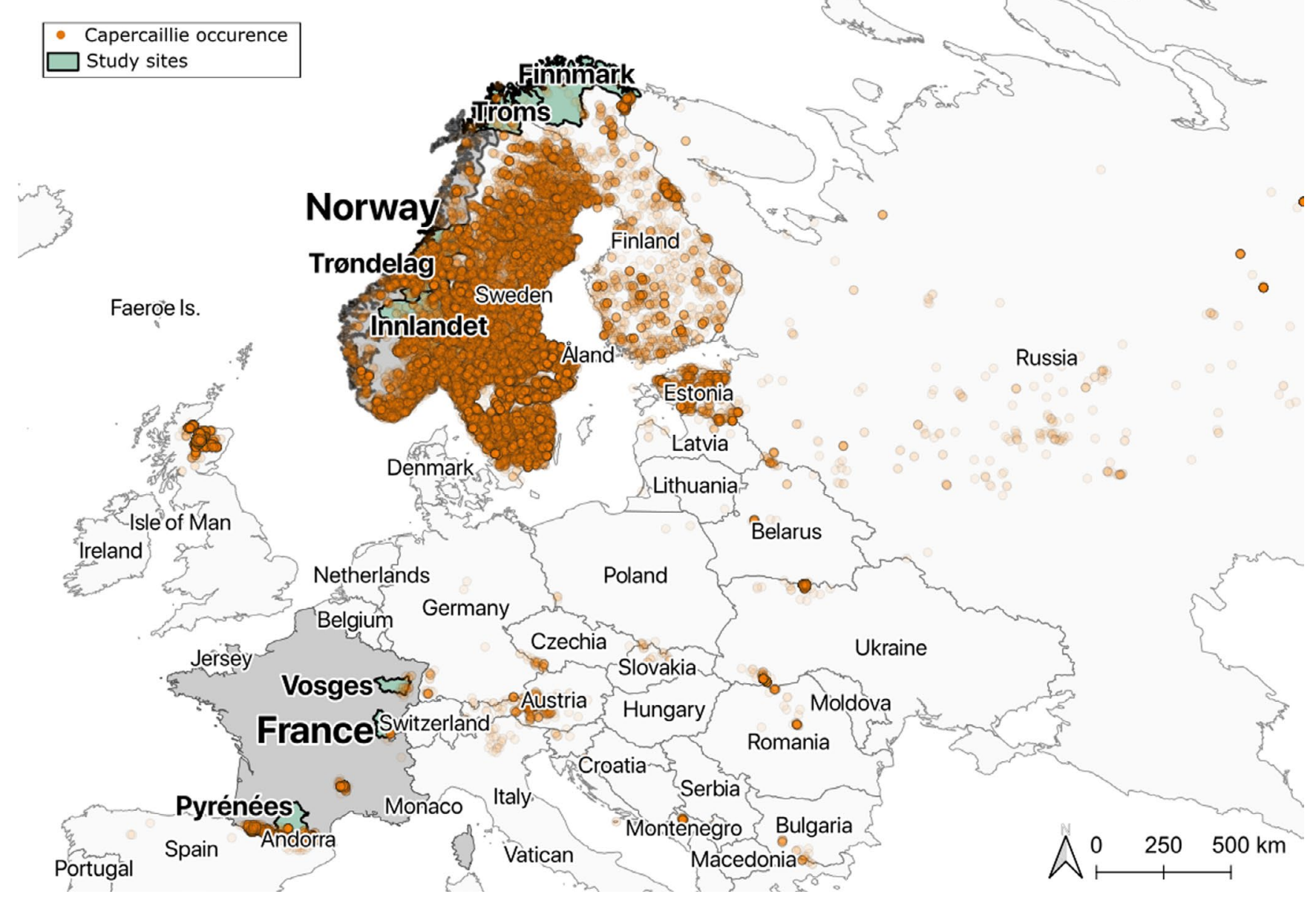

FIGURE 1 Map showing the occurrence of capercaillies in the past ten years (GBIF.org (04 March 2021) GBIF Occurrence Download https://doi.org/10.15468/dl.ucn5ce), and where capercaillie fecal samples were collected for this study $(n=232)$. Four of the study sites are located in Norway (Finnmark $n=6$, Troms $n=23$, Trøndelag $n=56$, and Innlandet $n=106$ ), while three are located in France (Vosges $n=30$, Jura $n=18$, and Pyrenees $n=20$ ). Created with QGIS version 3.10.4

samples with one extraction blank (with no fecal material) included in each batch. DNA extracts were stored at $-20^{\circ} \mathrm{C}$.

To characterize the diet of the western capercaillie, we used a universal primer set for plants targeting the P6 loop of the trnL intron; forward primer trnL-g (5'-GGGCAATCCTGAGCCAA-3') and reverse primer trnL-h (5'-CCATTGAGTCTCTGCACCTATC-3') (marker length: 10bp to 143bp, excl. primers) (Taberlet et al., 2007). Using oligotag, 15 tags of six nucleotides in length were designed and added to the 5 ' end of the forward and reverse primer. The tags were designed to have a minimal hamming distance of three. An additional one or two nucleotides were added to the 5 ' end of each tag to increase complexity on the flow cell (De Barba et al., 2014). To screen for PCR inhibition and determine the number of cycles for PCR amplification (Murray et al., 2015), we performed quantitative PCR (qPCR) on a dilution series (1:1, 1:5, 1:10) of a subset of the sample DNA extracts (25 samples) and on the positive control (leaf DNA extracts from Cinchona officinalis, a species that is not native to Europe). Conditions of the qPCR screening is detailed in the Appendix S2. The qPCR screening indicated that using $1 \mu$ of neat sample DNA extract and running 35 cycles were optimal for the subsequent tagged PCR amplification. Amplification and dissociation curves confirmed that only primer-dimers, and not target DNA, were present in the negative extraction controls. Tagged PCRs were carried out with three PCR replicates for each DNA extract, extraction negative control, positive control, and PCR negative control. A total of eight extraction negative controls, 10 PCR negative controls, and seven positive controls (all the same Cinchona officinalis DNA extract) were included in the study. PCR replicates were tagged using non-matching nucleotide tag combinations (e.g., forward primer tag 1 - reverse primer tag 2, forward tag 2 - reverse tag 3). Tagged PCRs were carried out as in the qPCR, although omitting the SYBR Green/ROX solution, adding an extension time of $72^{\circ} \mathrm{C}$ for 7 min instead of the dissociation curve, and using 35 PCR cycles. For each PCR negative control, $1 \mu \mathrm{l}$ of AccuGENE Molecular Biology Water was included instead of template DNA. Up to 2 PCR negative controls were used per PCR reaction. Visualization of amplified PCR products was done on a $2 \%$ agarose gel with GelRed against a 50 bp ladder. Amplification was considered successful if PCR products were between $60 \mathrm{bp}$ and 200 bp when visualized on the agarose gel. Extraction and PCR negative controls did not show any bands on the agarose gel. 
Prior to library building, PCR products were kept for pooling if at least two of the three PCR replicates for each sample were successfully amplified. PCR products were pooled together without repeated nucleotide tag combinations. This resulted in six amplicon pools, each containing 72 to 124 PCR replicates with different nucleotide tag combinations within each pool. Extraction, PCR negative controls and positive controls were included in each amplicon pool. We purified the six amplicon pools using MagBio HighPrep beads (2.8x bead to amplicon pool ratio), eluted in $50 \mu \mathrm{l}$ of EB buffer (Qiagen) and quantified using a Qubit Flex Fluorometer dsDNA HS Assay (Invitrogen). We followed the Tagsteady library preparation protocol to prepare the purified amplicon pools for sequencing (Carøe \& Bohmann, 2020). Amplicon libraries were purified using MagBio HighPrep beads (1.2x bead to library ratio) and eluted in $30 \mu \mathrm{l}$ of EB buffer. Quantification of purified amplicon libraries was carried out with qPCR, using the NEBNext Library Quant Kit for Illumina (New England BioLabs Inc). The six purified amplicon libraries were pooled in equimolar ratios and sequenced using 150 paired-end chemistry on the Illumina Miseq V3 sequencing platform (with 15\% PhiX) at the GeoGenetics Sequencing Core, University of Copenhagen, aiming at 35,000 paired reads per PCR replicate.

\subsection{Data analysis}

Sequence data were analyzed using the OBITools package (Boyer et al., 2016). Prior to data processing with OBITools, paired reads were merged using SeqPrep (https://github.com/jstjohn/SeqPrep, v1.2) with default parameters. Sequences were assigned to PCR replicates with ngsfilter using a $100 \%$ match to tags and maximum one bp mismatch to primers. Obiuniq was then used for merging strictly identical sequences. Denoising was carried out with obigrep: sequences with only a single copy (singletons) and/or shorter than 10 bp were removed (Baamrane et al., 2012; Hibert et al., 2013). This 10 bp cutoff size was also based on the shortest reference sequences in the reference database used, which are $11 \mathrm{bp}$ in length and derived from Equisetum and liverwort genera such as Herbertus and Moerckia. Amplification and sequencing errors were identified using obiclean using a threshold ratio of $5 \%$ between the main "head" sequence and the putative erroneous "internal" sequence (Bellemain et al., 2013; De Barba et al., 2014). We removed sequences identified as "internal," keeping only "head" sequences. Taxonomic assignment was carried out with ecotag, using the global EMBL reference database (release r143 from April 2020) (https://www.ebi.ac.uk/) that was generated using ecopcr, and with a local reference database (ArctBorBryo) containing 2280 reference sequences (1053 unique) of the trnL p6 loop from 2001 different arctic and boreal vascular plants and bryophytes (Soininen et al., 2015; Sønstebø et al., 2010; Willerslev et al., 2014). For all samples, we prioritized matches against the local ArctBorBryo reference database as it has better accuracy identifying species found in the boreal area (Alsos et al., 2016) but no local reference database was available for France. Post-OBITools sequence filtering and merging of the taxonomic assignments were carried out with a custom R script (https://github.com/Y-Lammers/ MergeAndFilter). To balance the removal of false positive and negatives, we used an intermediate stringent filtering in which we keep the sequences fulfilling all of the following criteria: (i) matched $98 \%$ to either reference database (using $98 \%$ rather than $100 \%$ allows identification of taxa missing in either reference library), (ii) had a minimum of 3 reads for each taxon observed within a PCR replicates, and (iii) occurring in at least two PCR replicates of a sample (Alsos et al., 2018; Ficetola et al., 2015). Following this sequence filtering, samples with less than 100 total reads were discarded. Remaining sequences fell into following four categories: (1) the taxon identifications from both databases were identical, (2) the taxon identifications matched at the family level but differed at the genus and/or species level, (3) the sequence was identified with only one database and not found in the other, and (4) the taxon was determined to be a contaminant/not plausible based on the known distribution of the taxon. The identified taxa for sequences in category 2 were based on matches to ArctBorBryo if it had the same or higher percentage identity than EMBL. Otherwise, identified taxa were based on matches to EMBL. Sequences in category 4 were removed as false positives. We also checked the sequences found in extraction and PCR negative controls for possible contamination. Sequences that were found only in positive controls or with higher number of reads in negative controls than in samples were removed (Appendix S1: Table S3). As the P6 loop contains homopolymers, we distinguished Vaccinium species based on the homopolymer-A and $T$ regions (Appendix S1: Table S4) (Chua et al., 2021) and merged homopolymers assigned to the same taxon. Information about resolving Vaccinium species based on homopolymer regions can be found in Appendix S2: Fig S1.1 and S1.2. Homopolymers are defined as sequences with five or more of the same nucleotides. The resulting list of plant taxa was grouped according to the following eight functional groups: trees, shrubs, dwarf shrubs, forbs, graminoids, aquatic macrophytes, vascular cryptogams, or bryophytes. Additionally, we checked that the assigned taxa were known from the geographical region using reference material online (https://www.biodiversi ty.no/, https://www.gbif.org/). To determine the number of potential new diet items, duplicated taxa were merged according to taxon name (e.g., Pinus1 and Pinus2 were merged to Pinus), resulting in 95 unique plant taxa (Appendix S1: Table S5). This list of unique plant taxa was subsequently matched against a known list of capercaillie diet items from existing literature using non-molecular approaches (Appendix S1: Table S6).

Statistical analyses were carried out using $\mathrm{R}$ (version 3.6.2). Sequences in samples were not rarefied prior to downstream analyses due to the possibility of introducing artificial variation through subsampling, loss of viable dietary information through loss of sequence counts, or exclusion of samples for analyses (McMurdie \& Holmes, 2014). To determine whether the subsequent statistical analysis should only be carried out on subsets of data due to uneven sampling of fecal samples collected from each season, we first carried out the Welch two-sample t test on the following datasets where samples were collected from both seasons: (1) Troms, (2) 
Innlandet, and (3) Troms and Innlandet combined. No significant differences between the tested datasets were found ( $p$-value $>0.05$ ). Hence, subsampling of our dataset for further statistical analysis according to seasons were not necessary.

To check whether sampling effort was sufficient to identify al diet items, we generated a species accumulation curve using the specaccum function, method "random," in vegan (Oksanen et al., 2012). The lomolino model was used to fit the accumulation curve and retrieve fitted values. The species accumulation curve generated was based on the diet richness identified in each fecal sample collected from each location. Diet richness analyses were based on the presence/absence of each plant taxa in each fecal sample and calculated as frequency of occurrence ( $F_{\circ} \%$ ) (Quéméré et al., 2013). For analysis of compositional differences, we used relative read abundance (RRA), which is the proportion of identified reads assigned to each plant taxon (Kartzinel et al., 2015; Soininen et al., 2009; Willerslev et al., 2014). Read counts were first transformed into RRA data using the vegan package with decostand function, which is a standardization method for community ecology (Oksanen et al., 2012). All statistical tests were assessed using the plant taxa identified.

Two separate multivariate analysis of variance (perMANOVA) models with 999 permutations were performed to test for the effect of location, season, and sex, on either the dietary richness or dietary composition found in each fecal sample. This was carried out using the adonis function in vegan (Anderson, 2001). To determine whether there were any dietary compositional differences between capercaillie populations within the same country, two additional perMANOVA models were performed on subsets of the data based on the country and it was collected from Norway and France. The results of the perMANOVA tests on these subsets are detailed in the Appendix S2. Dissimilarities in dietary composition between fecal samples collected from the three variables (locations, seasons, and sex) were quantified using the Bray-Curtis distance, with $K=3$ dimensions and 999 maximum iterations through the metaMDS function in vegan (Bray \& Curtis, 1957). The betadisper and permutest function with 999 permutations and bias adjustment was used to test for the perMANOVA assumption of homogeneity of multivariate dispersion (intraspecific dietary variation). For visualization of patterns, we used the nonmetric multidimensional scaling (NMDS) plot (Shepard, 1962a, 1962b) with an acceptable stress level of <0.2 (Clark, 1993) (Appendix S2: Fig S1.3). We also used the envfit function with 999 permutations to investigate which plant taxa may be involved in driving distribution patterns. Additionally, we ran an indicator taxa analysis using the indicspecies package to determine which plant taxa were strongly associated with a given variable (De Cáceres \& Legendre, 2009).

\section{3 | RESULTS}

\section{1 | Final dataset description}

After removing 60 samples dataset due to either unsuccessful PCR amplification (53 samples, 20 of them from one batch of samples collected from Innlandet, Norway (V01-V34)) or filtering parameters (7 samples) used in data analysis (Appendix S1: Tables S7 and S8), our final dataset consisted of 172 western capercaillie fecal samples. From these, 163 sequences with a minimum percentage identity of $98 \%$ to at least one taxon in the ArctBorBryo and/ or EMBL reference database $(16,477,6339$ reads) were kept after taxonomic assignment. Of the 163 sequences, 95 sequences had $100 \%$ match to ArctBorBryo (1,5010,048 reads), 136 sequences had $100 \%$ match to EMBL (16,386,507 reads), and 92 sequences had $100 \%$ match to both reference database $(15,003,823$ reads). The remaining sequences matched at $98 \%$ to either database and the non-matching part of the sequences primarily consisted of homopolymers (84,607 reads). Of the 163 sequences, 34 (20.9\%) were assigned to family level, 59 (36.2\%) to genus, and 67 (41.1\%) to species level. The remaining three sequences (1.8\%) were assigned to higher taxonomic levels ( 2 orders and 1 subclass). These three sequences (sequence ID: 4667, 6932, and 2048) were kept as they belonged to the bryophytes functional group, and bryophytes sequences are less well represented in trnL P6 loop reference databases (Alsos et al., 2018).

\section{2 | Dietary richness}

After merging of homopolymers, a total of 122 plant taxa were identified before merging of duplicated taxa according to taxon name. For example, Pinus1 and Pinus2 were each counted as a separate plant taxon as these sequences represent different species within the Pinus genus. We kept them as separate taxon as more than one Pinus species can be found in France. From these 122 plant taxa, 119 taxa identified to at least family level; these comprised 46 families, 68 genera, and 46 species from eight functional groups (trees, shrubs, dwarf shrubs, forbs, graminoids, aquatic macrophytes, vascular cryptogams, or bryophytes; Table 1). Of the taxa, $37.7 \%$ could be identified to species level, $33.6 \%$ at the genus level, and $28.7 \%$ at the family level. The species accumulation curve reached an estimated asymptote at 153 plant taxa, suggesting that our sampling effort was almost sufficient to capture the full plant diet of the capercaillies where 122 out of a possible 153 plant taxa were detected (Appendix S2: Fig S2.1). For the Norwegian population, a total of 114 taxa were identified (93.4\% of all identified plant taxa). The taxonomic resolution was $23.7 \%$ (27 taxa) at family level, $36.0 \%$ at genus level (41 taxa), and $37.7 \%$ at species level (42 taxa). The remaining three taxa $(2.6 \%)$ were identified to higher taxonomic levels. For the French population, a total of 59 taxa were identified $(48.4 \%$ of all identified plant taxa). Of these taxa, $28.8 \%$ were assigned to family level (17 taxa), 44.1\% at genus level (26 taxa), and $27.1 \%$ at species level (16 taxa).

Based on the frequency of occurrence among samples, the most frequently occurring groups of plants were trees (39.1\%), followed by forbs (16.4\%) and dwarf shrubs (16.1\%). The least occurring plants were aquatic macrophytes (0.2\%), occurring in only $1.2 \%$ of samples (2 samples) (Appendix S1: Table S9). Shrubs 
TAB LE 1 Frequency of occurrence $\left(F_{0} \%\right)$ of plant families found across all samples $(n=172)$. For species and genera identified within each family, see Appendix S1: Table S5

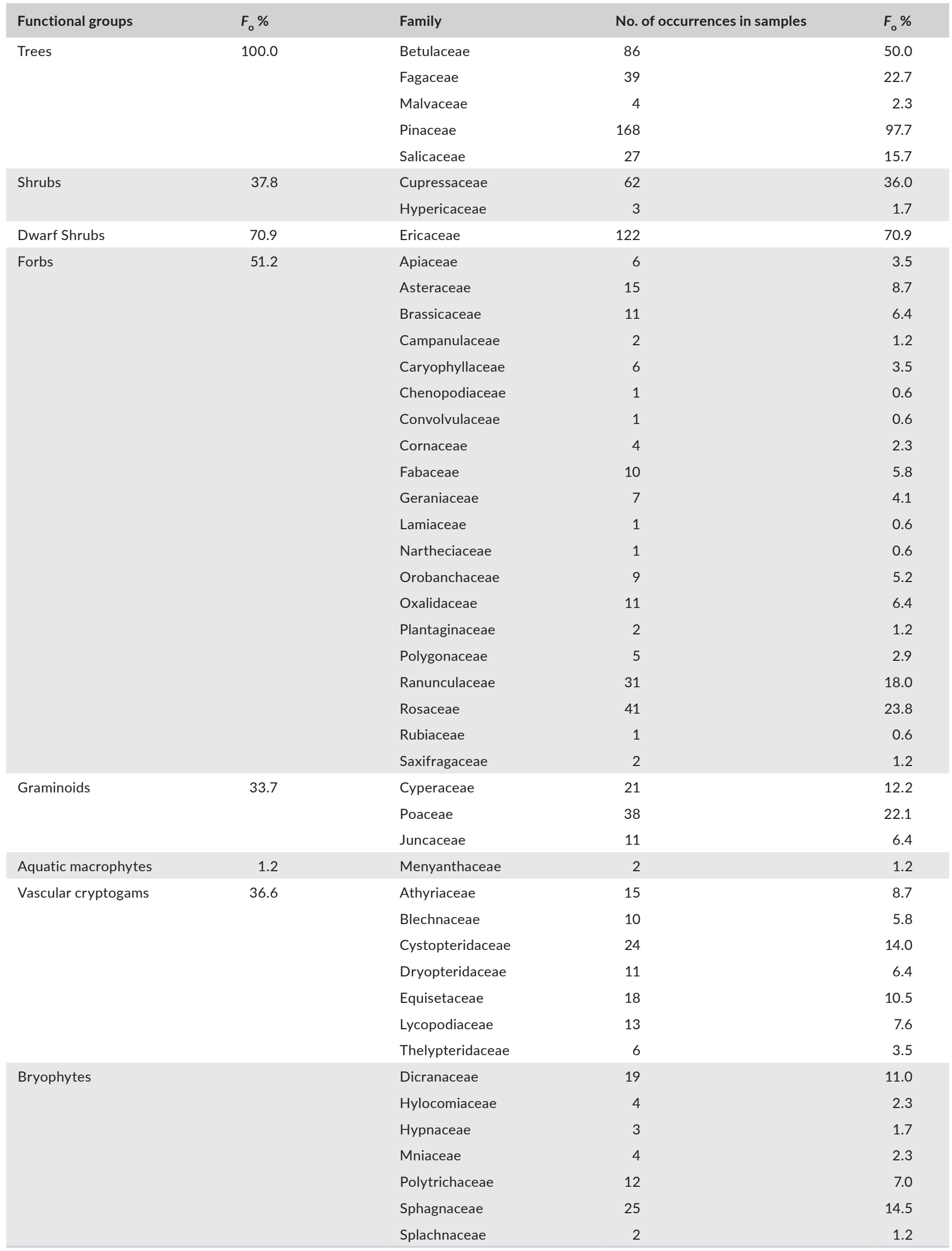


(5.0\%), bryophytes (6.8\%), vascular cryptogams (7.6\%), and graminoids $(8.8 \%)$ made up the rest of the plants found in capercaillie fecal samples (Appendix S2: Fig S2.2). The two most frequently occurring plant families consumed were Pinaceae $(97.7 \%$ occurrence across all samples) and Ericaceae (71.1\%) (Table 1). The most common taxon of the Pinaceae family was Pinus (58.8\% of all Pinaceae), while Vaccinium myrtillus (54.7\%) was the most commonly identified taxon from the Ericaceae family (Appendix S2: Fig S2.3). Between autumn and spring, there was a significant difference in the $F_{O} \%$ of both Pinaceae and Ericaceae found across all samples (Two-sample $T$ test, $p$-value $<0.05$ )

From each fecal sample, we identified on average seven plant taxa (SD: \pm 5 , range: $1-27$ ). Only $2.3 \%$ of samples contained just one plant taxa (monodiets). The average dietary richness for samples collected between locations varied from 5.7 taxa in Troms, to 9.7 taxa in Finnmark (Table 2). There was a significant differences in dietary richness between samples collected from the seven different locations (adonis pseudo $F_{6,40}=7.91, r^{2}=0.19, p=0.001$ ) and between seasons (adonis pseudo $F_{2,65}=0.55, r^{2}=0.01, p=0.007$ ). There were no significant differences in dietary richness between sexes (adonis pseudo $F_{1,57}=0.32, r^{2}=0.01, p=0.088$ ). Of the 122 plant taxa retrieved, capercaillies located in Trøndelag fed on the largest diversity of taxa identified at 87 taxa, while the lowest diversity of plants identified were from the Jura population at 23 taxa (Table 2). In the French population, Fagaceae trees (beech) were found in $66.7 \%$ of the fecal samples analyzed (Appendix S1: Table S10). Additionally, we retrieved 23 plant taxa that were found only in female capercaillie's fecal samples, while 16 plant taxa were found only in the male capercaillie's fecal samples (Appendix S1: Table S11). Seasonwise, 27 plant taxa were identified only from spring samples, while 25 plant taxa were identified only from autumn samples (Appendix S1: Table S12).

\section{3 | Dietary composition}

Similar to the dietary richness data, the highest relative read abundance (RRA) of consumed plant taxa were trees, dwarf shrubs, and forbs, making up $66.5 \%, 15.8 \%$, and $7.5 \%$ of the total RRA, respectively (Appendix S2: Fig S3.1). Plant taxa belonging to these three functional groups were found in samples collected in all locations, seasons, and in both sexes (Appendix S2: Figs S3.2 and S3.3). The least consumed plants were aquatic macrophytes (RRA 0.02\%), found in only two samples (Appendix S1: Table S13). The two families with the highest RRA were Pinaceae (56.9\%) and Ericaceae (15.8\%), and the main taxa making up the Pinaceae family was Pinus $(70.3 \%$ of all Pinaceae), while Vaccinium myrtillus (65.4\%) formed the majority of Ericaceae (Appendix S2: Fig S3.4). There was a significantly higher proportion of RRA of Pinaceae found in samples from spring (average $0.4 \%$ ) than autumn (average $0.2 \%$, Two-sample $T$ test, $p$ value $<0.05$ ), but there was no significant difference for Ericaceae (Two-sample $T$ test, $p$-value $=0.39$ ) (Appendix S2: Fig S3.5). The proportion of reads assigned to the plant functional groups at each location, separated by sex and season, is visualized in Figure 2a,b.

The perMANOVA test (with Bonferroni $p$-value correction) for the effects of variables (location, sex, and season) on the dietary composition based on RRA at the level of plant taxa showed that there was a significant difference between fecal samples collected from the different locations (adonis pseudo $F_{5,86}=11.01, r^{2}=0.17$, $p=0.001$ ) and between seasons (adonis pseudo $F_{2,03}=0.64, r^{2}=$ $0.01, p=0.036$ ) (Figure 3a). There were no significant differences in dietary composition between males and females across all fecal samples (adonis pseudo $F_{1,63}=0.51, r^{2}=0.01, p=0.095$ ). However, there was a significant difference in dietary composition between fecal samples collected from males and females at each individual location (adonis pseudo $F_{1,47}=2.77, r^{2}=0.04, p=0.024$ ) (Figure $3 b$ ).

\begin{tabular}{lllll} 
& Number of taxa & $\begin{array}{l}\text { Diet richness per } \\
\text { sample (min-max) }\end{array}$ & $\begin{array}{l}\text { Average } \\
\text { dietary } \\
\text { richness }\end{array}$ & $\begin{array}{l}\text { Standard } \\
\text { deviation (SD) }\end{array}$ \\
\hline Location & & & \\
Finnmark $(n=6)$ & 32 & $4-17$ & 9.7 & 4.6 \\
Troms $(n=19)$ & 37 & $1-11$ & 5.7 & 2.8 \\
Trøndelag $(n=50)$ & 87 & $1-27$ & 8.9 & 5.8 \\
Innlandet $(n=53)$ & 77 & $2-25$ & 6.3 & 4.6 \\
Vosges $(n=17)$ & 34 & $1-14$ & 7.2 & 3.4 \\
Jura $(n=14)$ & 23 & $2-11$ & 6.2 & 2.6 \\
Pyrenees $(n=13)$ & 33 & $2-19$ & 7.8 & 4.6 \\
\hline Sex & & & 7.2 & 4.3 \\
Males $(n=84)$ & 99 & $1-22$ & 7.5 & 5.2 \\
Females $(n=88)$ & 106 & $1-27$ & & \\
Season & & & 8.5 & 5.3 \\
Autumn $(n=70)$ & 95 & $1-27$ & 6.5 & 4.2 \\
\hline Spring $(n=102)$ & 97 & $1-25$ & & \\
\hline
\end{tabular}

TABLE 2 Dietary richness obtained from capercaillie fecal samples collected for each variable, with the number of taxa identified, minimum ( $\mathrm{min}$ ) and maximum (max) diet richness range, average, and standard deviation 
(a)
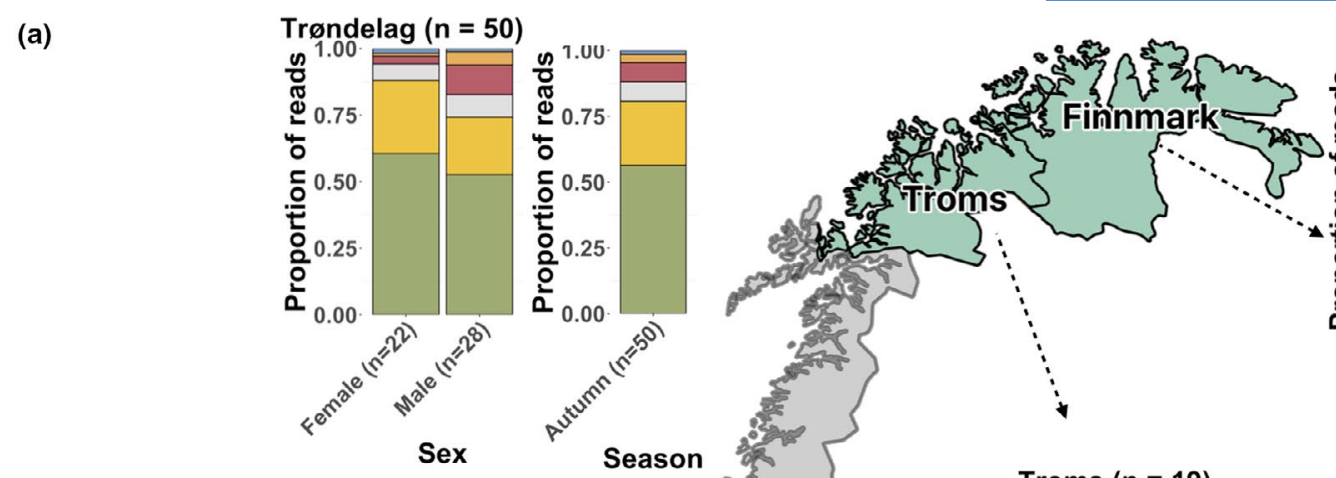

Finnmark $(\mathbf{n}=\mathbf{6})$
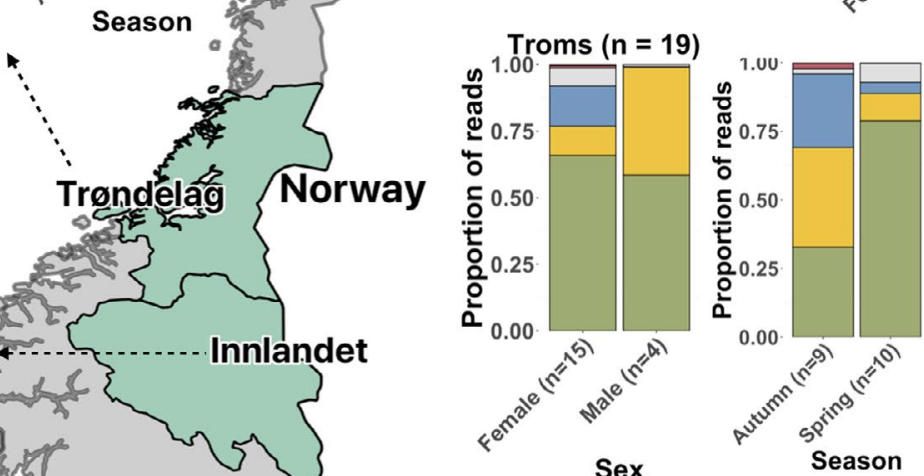

Functional groups
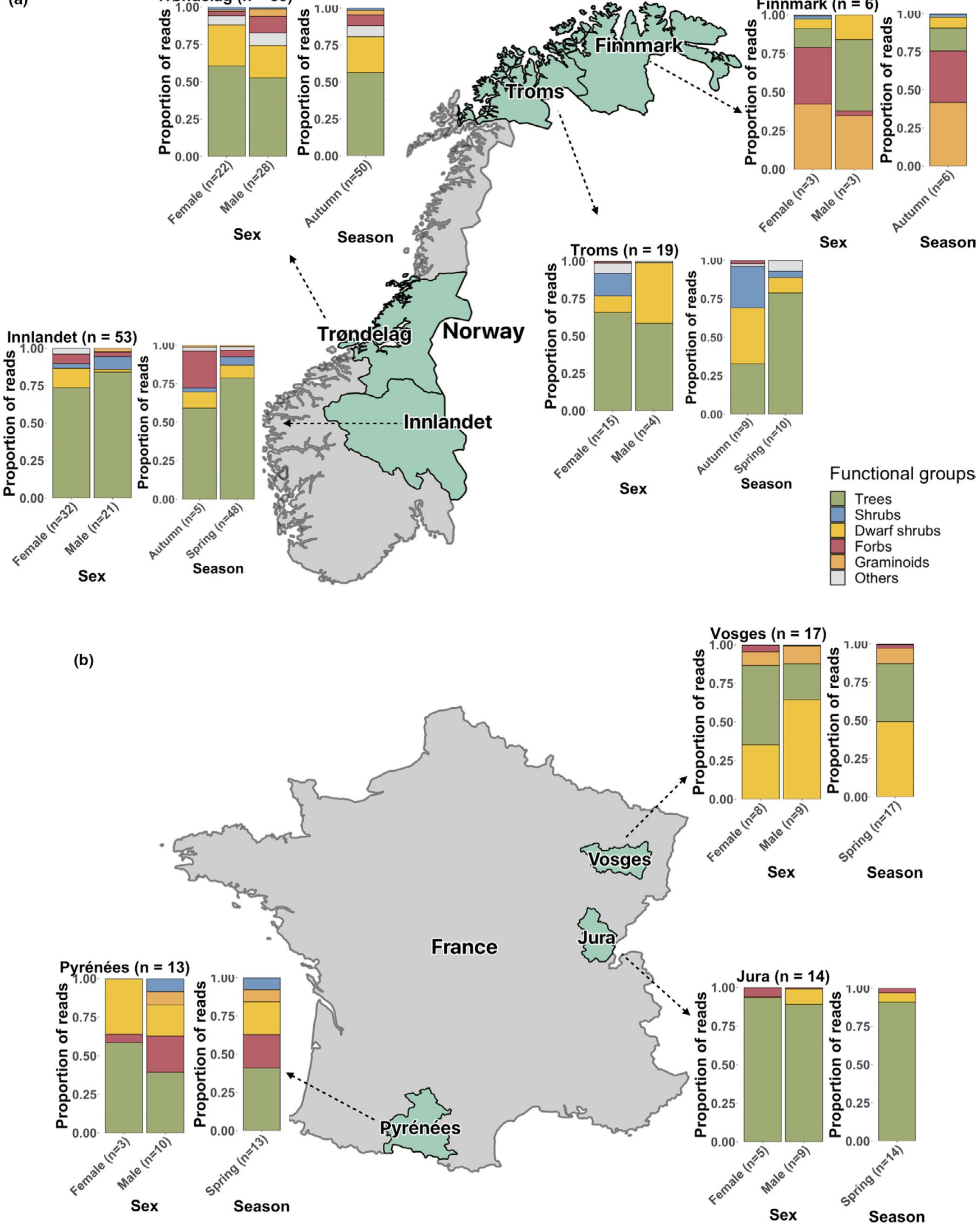

FIGURE 2 Stacked bar charts showing the proportion of reads assigned to functional groups between each location, sex, and season from capercaillie fecal samples collected in (a) Norway and (b) France 

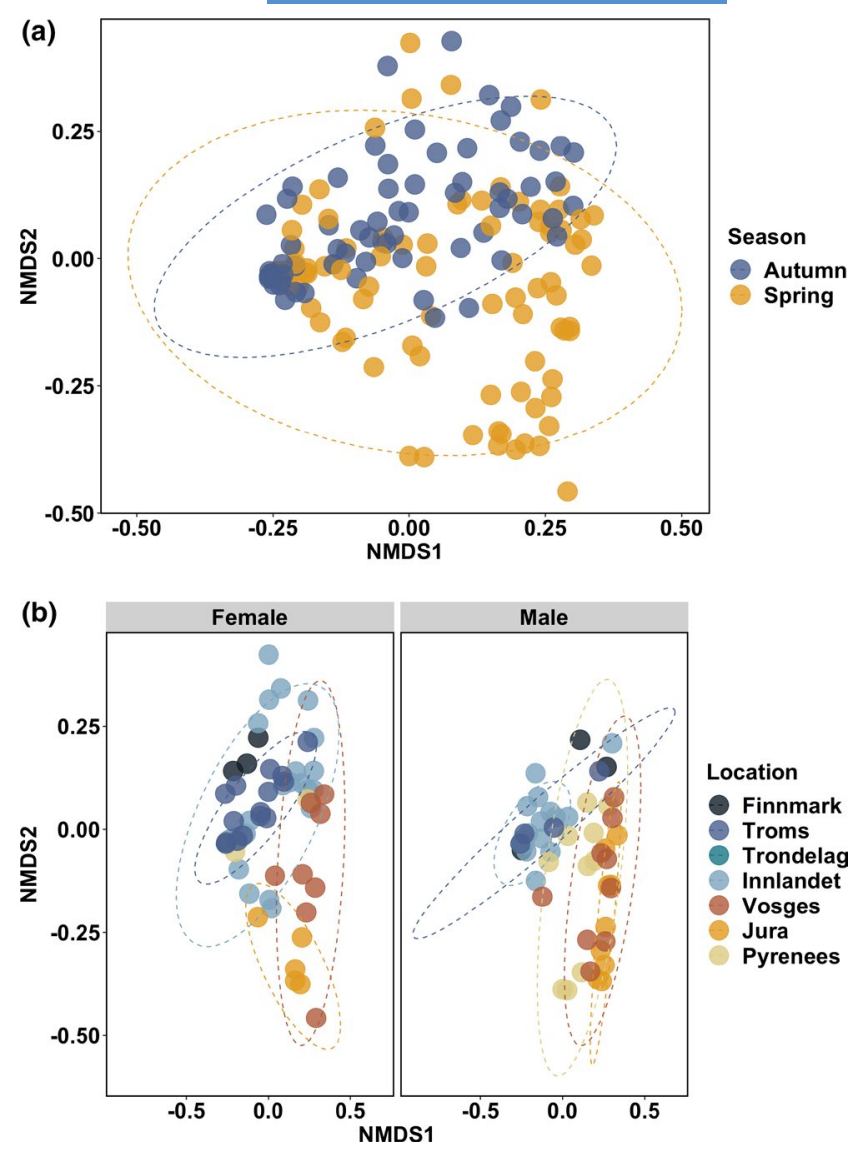

metabarcoding of 172 capercaillie fecal samples, we reconstructed a list of plant taxa $(n=122)$ consumed by capercaillies. All except three taxa were identified to minimum family level, and more than one-third of the taxa were identified at the species level (37.7\%). We highlighted the differences in dietary composition of populations located across the seven locations, between seasons and between sexes at each of the seven locations. Additionally, we also identified new diet items that were previously not recorded based on non-molecular methods, showing the potential of metabarcoding in retrieving a wider range of diet items, and at a better taxonomic resolution. From this, we learnt that capercaillie feeds on a wider range of plants than expected, suggesting that they can adapt their diet. This ecological information can be incorporated into the planning of appropriate conservation strategies for the western capercaillies.

Differences in diet observed between the analyzed capercaillie populations and seasons are expected, given that the vegetation varies from location and are subject to seasonal effects (Jacob, 1988; Saniga, 1998). Moreover, diet plasticity and individual preferences have been documented even within a small geographical location, and only few plant taxa have been recognized as being the main diet items throughout their range (González et al., 2012; Sedinger, 1997). The most frequently occurring group of plants with the highest RRA found in the analyzed capercaillie fecal samples were trees, dwarf shrubs, and forbs. Pinaceae and Ericaceae were the most frequently occurring families. This result is in accordance with previous studies on capercaillie diet based on non-molecular methods, which have shown that plants from these two plant famiFIGURE 3 NMDS plots of RRA-based Bray-Curtis dissimilarity
of capercaillie fecal samples collected from (a) different seasons (adonis pseudo $F_{2.03}=0.64, r^{2}=0.01, p=0.036$ ) and (b) both sexes from each of the seven locations (adonis pseudo $F_{1,47},=2.77, r^{2}=$ $0.04, p=0.024)$. The stress level of 0.163 is under the cutoff value of 0.2 for an interpretable ordination as suggested by Clark (1993)

The test for perMANOVA assumption of homogeneity of multivariate dispersion returned insignificant pseudo $F$ and permutative $p$-values $>0.05$, showing that while there is a difference in composition, there was no dispersion between variables tested which supports the assumption of homogeneity. The envfit test to uncover which plant taxa drive these results showed 16 plant taxa that were statistically significant $(p \leq 0.05)$ (Appendix S1: Table S14, Appendix S2: Fig S3.6). From the indicator taxa analysis based on locations, 20 plant taxa were strongly associated with a single location, while one taxon was strongly associated with four locations (Troms, Trøndelag, Innlandet, and Pyrenees) ( $p \leq 0.05$, Appendix S1: Table S15). Two plant taxa were strongly associated with samples collected from females, while three plant taxa were strongly associated with samples collected from males. For the seasons, 19 plant taxa were strongly associated with samples collected from autumn, while two plant taxa were strongly associated with samples collected from spring.

\section{4 | DISCUSSION}

Dietary information is a critical component in understanding animal ecology and effective conservation management. Through lies form the main components of their habitats and diet throughout the season, but the consumption of these plants shifts with changes in the season (Picozzi et al., 1996; Storch, 1993). During seasons where snow cover is greater such as in winter or early spring (Gjerde \& Wegge, 1989), pine needles are a critical resource for survivability when ground vegetation is scarce. By contrast, during summer and autumn, dependence on pine needles decreases as the availability of dwarf shrubs from the Ericaceae species, specifically bilberries (also called European blueberries, Vaccinium myrtillus), increases. This shift in diet consumption-from pine needles in the cold seasons to blueberries in the warmer seasons-has been well documented in non-molecular studies and are the main food items across their range (Blanco-Fontao et al., 2010; Quevedo et al., 2006; Rodrìguez \& Obeso, 2000; Storch, 1993). Also, in the present study, we show Pinaceae consumption is highest in spring when snow often still covers the ground, while Ericaceae consumption shows the opposite pattern with highest prevalence in the diet during autumn. The least occurring group of plants with the lowest RRA were aquatic plants, which were found in only two samples collected from female capercaillies in Norway. In each of these samples, the RRA of aquatic plants consumed comprised $6.1 \%$ and $0.2 \%$ of the diet, respectively. Despite consisting of only $6.1 \%$ of the total diet RRA for one individual, aquatic plants were the second most consumed plant group after dwarf shrubs (88.3\%). This result suggests that individual preferences can play a role in the diet retrieved, and a more varied diet may be observed from capercaillies living in heterogenous habitats. 
We had expected autumn samples to have a higher diet variety than spring samples, due to the presence of snow cover in spring which reduces access to ground vegetation. However, samples collected during the two seasons had almost the same number of taxa identified. This could be due to differences in snow cover between the individual locations even during the same collection period, making comparisons between seasons at different sites difficult. The almost complete absence of bryophytes and vascular cryptogams in the diet of the French capercaillie populations was also unexpected, given that mosses and ferns have been documented as part of their diet (Blanco-Fontao et al., 2010; Jacob, 1988; Rodriguez \& Obeso, 2000) and are present even in early spring. This may at least be partially explained by the strong presence of the Fagaceae trees (beech), which start to bud in winter and were found in $66.7 \%$ of the French samples. Studies have shown monodiet feeding on beech buds for several months in spring, as it is a more convenient source of food than mosses and ferns where snow cover is still heavy (Blanco-Fontao et al., 2010; Rodrìguez \& Obeso, 2000). Another reason could be that the trnL P6 loop reference data for bryophytes are not well represented, hence are not identified.

Monodiets, where only a single food item is consumed during a single foraging event is considered a common foraging pattern of capercaillies. During such foraging, they will perch for days or even weeks on individual trees to feed (Sedinger, 1997). In our study, we observe such a monodiet in only $2.3 \%$ of the fecal samples collected, with fecal samples containing on average eight different plant taxa. This may signal that the western capercaillies are moving more frequently over longer distances while foraging, at the expense of increasing energy expenditure to energy intake (Blanco-Fontao et al., 2010). Alternatively, metabarcoding is a more sensitive and powerful method to detect a larger variety of diet items within one fecal sample. This is supported by studies that have directly compared non-molecular methods and metabarcoding for reconstructing diet from the same individuals (Castle et al., 2020; Nichols et al., 2016). Another consideration could be that ingested plant DNA from prior meals are retained due to differential retention time, leading to the rarity of monodiets being observed using metabarcoding. However, folivores such as the capercaillies consume and digest food rapidly (Price et al., 2015), so monodiets should theoretically be detectable using metabarcoding.

Overall, there were no significant differences in the diet between males and females. However, when comparing between the sexes within each location, there was a significant difference in the dietary composition between males and females. Here, the diet of females was strongly associated with Alnus (from the Betulaceae family), which corresponds to a habitat partitioning study showing a strong association between females and birch trees (Betulaceae) (Bañuelos et al., 2008). As grouses are a sexually dimorphic family that exhibits habitat partitioning throughout the seasons (Connelly et al., 1989), we had expected to see this difference given that capercaillies are the most sexually dimorphic of all grouses (Bañuelos et al., 2008) and female reproductive needs would result in differential habitat and resource preferences as compared to males (Storch, 1993).
Due to the differences in diet observed throughout the capercaillies range, there is a need to collect localized data to develop effective conservation strategies. Important diet items may need to be protected in the capercaillie habitats, for example, by controlling grazing from livestock to aid in population recovery and prevent competition for food, which could lead to an increase in foraging time and, hence, greater exposure to predators (Selas, 2000). Particularly in France (Vosges and Jura), where the capercaillie populations have reduced significantly in the past few decades despite ongoing conservation efforts (Montadert, 2012; Sachot et al., 2006; Segelbacher et al., 2003), our study provides insights into resource use. Here, conservation measures may be tailored to include our findings, by including a focus on preserving the main diet items across its range. To assess the importance of these diet items for the survival of the species, additional data on nutritional qualities are required to definitively address which diet items are most important to conserve relative to their availability. Nevertheless, the wide range of diet items retrieved from our study could indicate that vegetation may not limit food intake for capercaillies, suggesting dietary plasticity in this species. Such plasticity suggests that threats to their survivability may not be resource-related, but rather, other factors such as chick predation or disturbances at mating grounds and during breeding season may play a more pertinent role in the species' decline (Brenot et al., 1996; Wegge \& Kastdalen, 2008). Alternatively, this plasticity in their diet could imply that good habitat quality with access to a diverse array of food resources might be an important factor in their survival. As an umbrella species, protection of the capercaillies' habitat would also indirectly benefit other taxa living in the same habitat such as wolves, lynxes, owls, and woodpeckers (Mikoláš et al., 2015; Suter et al., 2002). Hence, conservation strategies targeted at the protection of the capercaillies' habitat has a broader conservation implication on the diversity found within these habitats. However, observed dietary differences could be due to individual preferences instead of dietary plasticity at the population level. It is recommended that future studies with detailed information on food availability should be carried out to better discern if capercaillies use resources opportunistically or selectively.

Utilizing metabarcoding for the reconstruction of capercaillie diet has allowed us to retrieve more diet items (122 taxa) and at a higher taxonomic resolution based on 172 samples than non-molecular techniques. Even though our sampling did not reach asymptote to retrieve the full range of diet items consumed by the western capercaillies, our sampling effort could capture at least $80 \%$ of all diet items. Of these 122 taxa, 35 are potentially new diet items that have not been documented in decades of capercaillie diet research using non-molecular means. The inclusion of a captive capercaillie in our dataset did not yield any new diet items that were not also consumed by wild populations. To date, non-molecular capercaillie diet studies identified on average around 10-30 taxa per study, even with large sample sizes (Blanco-Fontao et al., 2010; Borchtchevski, 2009; González et al., 2012; Jacob, 1988; Odden et al., 2003; Picozzi et al., 1996, 1999; Rodriguez \& Obeso, 2000; Rolstad, 1988; Wegge $\&$ Kastdalen, 2008). Metabarcoding increases diet identification and 
retrieved up to 12 times more taxa as demonstrated in our study. Current dietary information on the western capercaillies is primarily based on non-molecular techniques and typically limited to a restricted geographic region and/or very small sample sizes. In Norway and France-the focus areas of the present study-capercaillie diet studies have been restricted to chicks or populations located in South-East Norway (Odden et al., 2003; Rolstad, 1988; Wegge \& Kastdalen, 2008) or are based on only a few individuals in France (Brezard, 1980; Jacob, 1988). With metabarcoding, the generation of data can come at a much faster pace (Nichols et al., 2016) and also provides a fuller overview of the diet consumed since fully digested plant fragments can be identified. In comparison, nonmolecular methods such as microhistology are less sensitive and require trained experts to accurately identify plant fragments and digested fragments are easily missed (Nichols et al., 2016; Sheppard \& Harwood, 2005; Shrestha \& Wegge, 2006). Moreover, in a study carried out by Nichols et al. (2016) five years ago, they estimated that metabarcoding only costs $€ 115$ per sample as compared to $€ 300$ using microscopy. Currently, the costs of metabarcoding have decreased due to optimized protocols such as using the Tagsteady library-building protocol to prevent tag jumps (Carøe \& Bohmann, 2020; Schnell et al., 2015), or decrease in sequencing prices. With continuous improvements in protocols and technology, a further decrease in costs is expected in the future. Thus, non-molecular methods are also much more expensive with the high time-to-salary costs incurred for analysis.

Our study showcases the high potential of metabarcoding in providing more in-depth information for the understanding of species ecology. However, our study also exemplifies that there are some limitations of this method in diet analysis. First, around $22 \%$ (53 samples) of samples failed to amplify during the PCR amplification process. We suspect that the main reason for PCR failure was the way that the samples were stored and transported before DNA extraction. Fecal samples were not kept cool immediately following collection which could have led to DNA degradation, affecting the DNA yield (Nsubuga et al., 2004). When working with fecal samples that are rare and difficult to collect, care has to be taken to minimize the risk of DNA degradation, for example by collecting samples in silica gel. Second, while the high sensitivity of metabarcoding is great for enhanced taxa detectability as compared to non-molecular methods, there is the risk of artificially inflating dietary breadth due to potential contamination. The inclusion of extraction and PCR negative controls allowed us to check for possible contaminants and remove them from our dataset. Manual curation of taxonomically identified sequences was also an essential step in removing food contaminants not found in study areas. For example, we removed sequences corresponding to ginger as ginger plants are non-native and were not present at our study sites. Third, the comprehensiveness of the reference database used for taxonomic assignment is an important consideration. The species resolution of taxa detected from the Norwegian population was $37.7 \%$ as compared to $27.1 \%$ for the French population. This better taxonomic resolution for the Norwegian samples can be explained by the local reference database used for arctic plants, something that is missing for Central-Southern European plants. Hence, we can argue that the power and sensitivity of metabarcoding over non-molecular techniques rely on the reference database available. Due to the lack of coverage or poor resolution for certain families using the trnL P6 loop such as Asteraceae, Cyperaceae, Rosaceae, and Poaceae (Alsos et al., 2018; De Barba et al., 2014), care has to be taken in interpreting the absence of taxa in diet. The diet detected by metabarcoding should be taken as a minimum diet, with the possibility that other diet items may go undetected using this method. Last, metabarcoding is unable to discern which part of the plants are consumed, which may be an important aspect of studies determining energy intake and expenditure. Such studies would have to rely on non-molecular means in addition to utilizing metabarcoding.

In conclusion, our results provide the most complete view on capercaillie plant diet to date and highlight the need for dietary studies to be conducted at different spatial and temporal scales in order to obtain a complete view of a species' diet. The advantages of metabarcoding over non-molecular techniques in studying animal diet support its use for future diet studies, but careful consideration of its limitations should be taken into account. Depending on research needs, metabarcoding may have to be used in conjunction with other non-molecular techniques in diet studies.

\section{ACKNOWLEDGEMENTS}

For generating the Illumina data, we would like to thank the staff at the Danish National High-Throughput Sequencing Centre. We would like to extend our gratitude to Alex Crampton-Platt (NatureMetrics), Arne Flor, Bjørn Morten Baardvik, Joy Coppes, Kat Bruce (NatureMetrics), Marc Montadert (France National agency for wildlife), Stein Nilsen, and Stephanie Witczak for providing relevant contact information, details about capercaillies, or contributing to the development of this work. For sample collection, we would like to thank the following group of people without whom this research would not have been possible; Alexandra Depraz (Groupe Tétras Jura), Bjørn-Roar Hagen, Camilla Hjorth Scharff-Olsen, Christophe Lhez, Hans Christian Pedersen, Kevin Foulché, Kristine Vesterdorf, Maria Ariza Salazar, Per Gustav Thingstad, Pål Fossland Moa, Stéphane Roche, Stian Rembjør Almstad, Torbjørn Alm, and Unni Bjerke Gamst. Additionally, we are grateful to Per Wegge and Françoise Preiss (Groupe Tétras Vosges) for invaluable inputs to the writing of this manuscript and for sample collection. This research is part of the H2020 MSCA-ITN-ETN Plant.ID network and has received funding from the European Union's Horizon 2020 research and innovation programme under grant agreement No 765000.

\section{CONFLICT OF INTEREST}

There is no conflict of interest.

\section{AUTHOR CONTRIBUTIONS}

PYSC, KB, SB, and IGA designed the research; PYSC, TE, and EM collected samples; PYSC performed laboratory work; YL did the bioinformatic analysis; PYSC did the post-OBITools data analysis; PYSC 
did the statistical analyses; EM provided details on known/unknown diet of capercaillies; PYSC made the figures and wrote the paper with input from YL, TE, EM, KB, SB, and IGA. All authors contributed to the final version of the submitted manuscript.

\section{DATA AVAILABILITY STATEMENT}

All sequenced data and scripts used for generating data are available on DRYAD, DOI: https://doi.org/10.5061/dryad.dfn2z3524

\section{ORCID}

Physilia Ying Shi Chua (DD https://orcid.org/0000-0001-7229-4480

Youri Lammers (D) https://orcid.org/0000-0003-0952-2668

Torbjørn Ekrem (D) https://orcid.org/0000-0003-3469-9211

Kristine Bohmann (D) https://orcid.org/0000-0001-7907-064X

Sanne Boessenkool (D) https://orcid.org/0000-0001-8033-1165

Inger Greve Alsos (iD https://orcid.org/0000-0002-8610-1085

\section{REFERENCES}

Alsos, I. G., Ehrich, D., Seidenkrantz, M. S., Bennike, O., Kirchhefer, A. J. $\&$ Geirsdottir, A. (2016). The role of sea ice for vascular plant dispersal in the Arctic. Biology Letters, 12(9), https://doi.org/10.1098/ rsbl.2016.0264

Alsos, I. G., Lammers, Y., Yoccoz, N. G., Jørgensen, T., Sjögren, P., Gielly, L., \& Edwards, M. E. (2018). Plant DNA metabarcoding of lake sediments: How does it represent the contemporary vegetation. PLoS One, 13(4), 1-23. https://doi.org/10.1371/journ al.pone. 0195403

Anderson, M. J. (2001). A new method for non-parametric multivariate analysis of variance. Austral Ecology, 26(1), 32-46. https://doi. org/10.1111/j.1442-9993.2001.01070

Aziz, S. A., Clements, G. R., Peng, L. Y., Campos-Arceiz, A., McConkey, K. R., Forget, P.-M., \& Gan, H. M. (2017). Elucidating the diet of the island flying fox (Pteropus hypomelanus) in Peninsular Malaysia through Illumina Next-Generation Sequencing. PeerJ, 5, e3176.

Baamrane, M. A., Shehzad, W., Ouhammou, A., Abbad, A., Naimi, M., Coissac, E., Taberlet, P., \& Znari, M. (2012). Assessment of the food habits of the Moroccan dorcas gazelle in M'Sabih Talaa, west central Morocco, using the trnL approach. PLoS One, 7(4) , e35643. https://doi.org/10.1371/journal.pone.0035643

Bañuelos, M. J., Quevedo, M., \& Obeso, J. R. (2008). Habitat partitioning in endangered Cantabrian capercaillie Tetrao urogallus cantabricus. Journal of Ornithology, 149(2), 245-252. https://doi.org/10.1007/ s10336-007-0267-5

Bellemain, E., Davey, M. L., Kauserud, H., Epp, L. S., Boessenkool, S., Coissac, E., Geml, J., Edwards, M., Willerslev, E., Gussarova, G., Taberlet, P., \& Brochmann, C. (2013). Fungal palaeodiversity revealed using high-throughput metabarcoding of ancient DNA from arctic permafrost. Environmental Microbiology, 15(4), 1176-1189. https://doi.org/10.1111/1462-2920.12020

Bilodeau, F., Gauthier, G., Fauteux, D., \& Berteaux, D. (2014). Does lemming winter grazing impact vegetation in the Canadian Arctic? Polar Biology, 37(6), 845-857. https://doi.org/10.1007/s0030 0-014-1486-x

Blanco-Fontao, B., Fernández-Gil, A., Obeso, J. R., \& Quevedo, M. (2010). Diet and habitat selection in Cantabrian Capercaillie (Tetrao urogallus cantabricus): Ecological differentiation of a rear-edge population. Journal of Ornithology, 151(2), 269-277. https://doi. org/10.1007/s10336-009-0452-9

Borchtchevski, V. (2009). The May diet of Capercaillie (Tetrao urogallus) in an extensively logged area of NW Russia. Ornis Fennica, 86(1), 18-29.
Boyer, F., Mercier, C., Bonin, A., Le Bras, Y., Taberlet, P., \& Coissac, E. (2016). obitools: A unix-inspired software package for DNA metabarcoding. Molecular Ecology Resources, 16(1), 176-182. https:// doi.org/10.1111/1755-0998.12428

Bray, J. R., \& Curtis, J. T. (1957). An Ordination of the Upland Forest Communities of Southern Wisconsin. Ecological Monographs, 27(4), 325-349. https://doi.org/10.2307/1942268

Brenot, J. F., Catusse, M., \& Ménoni, E. (1996). Effets de la station de ski de fond du plateau de Beille (Ariège) sur une importante population de grand tétras (Tetrao urogallus). Alauda, 64(2), 249-260.

Brezard, J. M. (1980). Le grand tétras (Tetrao urogalus L.) dans la réserve domaniale de chasse du Mont Vallier. ENITEF-ONF. St Girons: 83 pp. (the Capercaillie in tne Natural Reserve of Mont Vallier, engineer's memory, France).

Carøe, C., \& Bohmann, K. (2020). Tagsteady: A metabarcoding library preparation protocol to avoid false assignment of sequences to samples. Molecular Ecology Resources, 20(6), 1620-1631. https:// doi.org/10.1111/1755-0998.13227

Castle, S. T., Allan, N., Clifford, D., Aylward, C. M., Ramsey, J., Fascetti, A. J., Pesapane, R., Roy, A., Statham, M., Sacks, B., \& Foley, J. (2020). Diet composition analysis provides new management insights for a highly specialized endangered small mammal. PLoS One, 15(10), e0240136. https://doi.org/10.1371/journal.pone.0240136

Ceballos, G., Ehrlich, P. R., Barnosky, A. D., García, A., Pringle, R. M., \& Palmer, T. M. (2015). Accelerated modern human-induced species losses: Entering the sixth mass extinction. Science Advances, 1(5), e1400253. https://doi.org/10.1126/sciadv.1400253

Ceballos, G., García, A., \& Ehrlich, P. R. (2010). The Sixth Extinction Crisis Loss of Animal Populations and Species. JournalofCosmology.com, 8. https://www.researchgate.net/publication/266231196

Chua, P. Y. S., Crampton-Platt, A., Lammers, Y., Alsos, I. G., Boessenkool, S., \& Bohmann, K. (2021). Metagenomics: A viable tool for reconstructing herbivore diet. Molecular Ecology Resources, 1-15. https:// doi.org/10.1111/1755-0998.13425

Clare, E. L. (2014). Molecular detection of trophic interactions: Emerging trends, distinct advantages, significant considerations and conservation applications. Evolutionary Applications, 7(9), 1144-1157. https://doi.org/10.1111/eva.12225

Clark, K. (1993). Non-parametric multivariate analyses of changes in community structure. Australian Journal of Ecology, 18(1), 117-143. https://doi.org/10.1111/j.1442-9993.1993.tb00438.x

Connelly, J. W., Bergerud, A. T., \& Gratson, M. W. (1989). Adaptive Strategies and Population Ecology of Northern Grouse. The Journal of Wildlife Management, 53(3), 857. https://doi.org/10.2307/3809228

Cracraft, J. (1995). The urgency of building global capacity for biodiversity science. Biodiversity \& Conservation, 4(5), 463-475. https://doi. org/10.1007/BF00056337

De Barba, M., Miquel, C., Boyer, F., Mercier, C., Rioux, D., Coissac, E., $\&$ Taberlet, P. (2014). DNA metabarcoding multiplexing and validation of data accuracy for diet assessment: Application to omnivorous diet. Molecular Ecology Resources, 14(2), 306-323. https://doi. org/10.1111/1755-0998.12188

De Cáceres, M., \& Legendre, P. (2009). Associations between species and groups of sites: Indices and statistical inference. Ecology, 90(12), 3566-3574. https://doi.org/10.1890/08-1823.1

Duriez, O., Sachet, J. M., Ménoni, E., Pidancier, N., Miquel, C., \& Taberlet, P. (2007). Phylogeography of the capercaillie in Eurasia: What is the conservation status in the Pyrenees and Cantabrian Mounts? Conservation Genetics, 8(3), 513-526. https://doi.org/10.1007/ s10592-006-9165-2

Erickson, D. L., Reed, E., Ramachandran, P., Bourg, N. A., McShea W. J., Ottesen A. (2017). Reconstructing a herbivore's diet using a novel rbcL DNA mini-barcode for plants. AoB PLANTS, 9, (3). http://dx.doi. org/10.1093/aobpla/plx015

Ficetola, G. F., Pansu, J., Bonin, A., Coissac, E., Giguet-Covex, C., De Barba, M., Gielly, L., Lopes, C. M., Boyer, F., Pompanon, F., Rayé, 
G., \& Taberlet, P. (2015). Replication levels, false presences and the estimation of the presence/absence from eDNA metabarcoding data. Molecular Ecology Resources, 15(3), 543-556. https://doi. org/10.1111/1755-0998.12338

Gjerde, I., \& Wegge, P. (1989). Spacing Pattern, Habitat Use and Survival of Capercaillie in a Fragmented Winter Habitat. Scandinavian Journal of Ornithology, 20(3), 219-225. https://doi.org/10.2307/3676916

González, M. A., Olea, P. P., Mateo-tomás, P., García-tejero, S., De frutos, Á., Robles, L., Purroy, F. J., \& Ena, V. (2012). Habitat selection and diet of Western Capercaillie Tetrao urogallus in an atypical biogeographical region. Ibis, 154(2), 260-272. https://doi. org/10.1111/j.1474-919X.2012.01217.x

Gustafsson, P. J. (2008). Distribution and structure of Capercaillie (Tetrao urogallus) leks in a Scandinavian mountain range area. Environmental Studies.

Hawlitschek, O., Fernández-González, A., Balmori-de la Puente, A., \& Castresana, J. (2018). A pipeline for metabarcoding and diet analysis from fecal samples developed for a small semi-aquatic mammal. PLoS One, 13(8), e0201763. https://doi.org/10.1371/journ al.pone. 0201763

Hibert, F., Sabatier, D., Andrivot, J., Scotti-Saintagne, C., Gonzalez, S., Prévost, M.-F., Grenand, P., Chave, J., Caron, H., \& Richard-Hansen, C. (2011). Botany, genetics and ethnobotany: A crossed investigation on the elusive tapir's diet in French guiana. PLoS One, 6(10), e25850. https://doi.org/10.1371/journal.pone.0025850

Hibert, F., Taberlet, P., Chave, J., Scotti-Saintagne, C., Sabatier, D., \& Richard-Hansen, C. (2013). Unveiling the Diet of Elusive Rainforest Herbivores in Next Generation Sequencing Era? The Tapir as a Case Study. PLoS One, 8(4), https://doi.org/10.1371/journ al.pone.0060799

IPBES (2019). In E. S. Brondizio, J. Settele, S. Díaz, \& H. T. Ngo (Eds.), Global assessment report on biodiversity and ecosystem services of the Intergovernmental Science-Policy Platform on Biodiversity and Ecosystem Services (pp. 1-56). IPBES secretariat.

Iwanowicz, D. D., Vandergast, A. G., Cornman, R. S., Adams, C. R., Kohn, J. R., Fisher, R. N., \& Brehme, C. S. (2016). Metabarcoding of fecal samples to determine herbivore diets: A case study of the endangered Pacific pocket mouse. PLoS One, 11(11), https://doi. org/10.1371/journal.pone.0165366

Jacob, L. (1988). Le régime alimentaire du grand tétras (Tetrao urogallus L.) et de la gélinotte des bois (Bonasa bonasia L.) dans le Jura. Acta Oecologica, 9(4), 347-370. Retrieved from http://www.theses. $\mathrm{fr} / 1987 \mathrm{DIJOSO09}$

Kartzinel, T. R., Chen, P. A., Coverdale, T. C., Erickson, D. L., Kress, W. J., Kuzmina, M. L., Rubenstein, D. I., Wang, W., \& Pringle, R. M. (2015). DNA metabarcoding illuminates dietary niche partitioning by African large herbivores. Proceedings of the National Academy of Sciences, 112(26), 8019-8024. https://doi.org/10.1073/pnas.15032 83112

Klaus, S., \& Bergmann, H. H. (1994). Distribution, status and limiting factors of capercaillie (Tetrao urogallus) in Central Europe, particularly in Germany, including an evaluation of reintroductions. Gibier Faune Sauvage, 11, 57-80. Retrieved from http://cat.inist.fr/?aMode le $=$ afficheN\&cpsidt $=3454160$

Kowalczyk, R., Wójcik, J. M., Taberlet, P., Kamiński, T., Miquel, C., Valentini, A., Craine, J. M., \& Coissac, E. (2019). Foraging plasticity allows a large herbivore to persist in a sheltering forest habitat: DNA metabarcoding diet analysis of the European bison. Forest Ecology and Management, 449, 117474. https://doi.org/10.1016/j. foreco.2019.117474

Kunz, T. H., de Torrez, E. B., Bauer, D., Lobova, T., \& Fleming, T. H. (2011). Ecosystem services provided by bats. Annals of the New York Academy of Sciences, 1223, 1-38. https://doi. org/10.1111/j.1749-6632.2011.06004.x
Lopes, C. M., De Barba, M., Boyer, F., Mercier, C., da Silva Filho, P. J. S., Heidtmann, L. M., Galiano, D., Kubiak, B. B., Langone, P., Garcias, F. M., Gielly, L., Coissac, E., de Freitas, T. R. O., \& Taberlet, P. (2015). DNA metabarcoding diet analysis for species with parapatric vs sympatric distribution: a case study on subterranean rodents. Heredity, 114(5), 525-536. https://doi.org/10.1038/ hdy.2014.109

McMurdie, P. J., \& Holmes, S. (2014). Waste not, want not: why rarefying microbiome data is inadmissible. PLoS Computational Biology, 10(4), 1003531. https://doi.org/10.1371/journal.pcbi.1003531

Mikoláś, M., Svitok, M., Tejkal, M., Leitão, P. J., Morrissey, R. C., Svoboda, M., Seedre, M., \& Fontaine, J. B. (2015). Evaluating forest management intensity on an umbrella species: Capercaillie persistence in central Europe. Forest Ecology and Management, 354, 26-34. https://doi.org/10.1016/j.foreco.2015.07.001

Mollet, P., Kéry, M., Gardner, B., Pasinelli, G., \& Royle, J. A. (2015). Estimating population size for capercaillie (Tetrao urogallus L.) with spatial capture-recapture models based on genotypes from one field sample. PLoS One, 10(6), 1-16. https://doi.org/10.1371/journ al.pone.0129020

Montadert, M. (2012). Partial recovery of capercaillie in French Jura Mountains. In Grouse News 44, Newsletter of the Grouse Group (pp. 9-14)

Moss, R., Leckie, F., Biggins, A., Poole, T., Baines, D., \& Kortland, K. (2014). Impacts of human disturbance on capercaillie tetrao urogallus distribution and demography in scottish woodland. Wildlife Biology, 20(1), 1-18. https://doi.org/10.2981/wlb.12065

Murray, D. C., Coghlan, M. L., \& Bunce, M. (2015). From benchtop to desktop: Important considerations when designing amplicon sequencing workflows. PLoS One, 10(4), e0124671. https://doi. org/10.1371/journal.pone.0124671

Nichols, R. V., Åkesson, M., \& Kjellander, P. (2016). Diet assessment based on rumen contents: A comparison between DNA metabarcoding and macroscopy. PLoS One, 11(6), e0157977. https://doi. org/10.1371/journal.pone.0157977

Nsubuga, A. M., Robbins, M. M., Roeder, A. D., Morin, P. A., Boesch, C., \& Vigilant, L. (2004). Factors affecting the amount of genomic DNA extracted from ape faeces and the identification of an improved sample storage method. Molecular Ecology, 13(7), 2089-2094. https://doi.org/10.1111/j.1365-294X.2004.02207.x

Observatoire des Galliformes de Montagne (2020). Bilan Décennal de I'OGM. Observatoire des Galliformes de Montagne.

Odden, M., Wegge, P., Eliassen, S., \& Finne, M. H. (2003). The influence of sexual size dimorphism on the dietary shifts of Capercaillie Tetrao urogallus during spring. Ornis Fennica, 80, 130-136.

Oksanen, A. J., Blanchet, F. G., Kindt, R., Legen-, P., Minchin, P. R., Hara, R. B. O., \& Stevens, M. H. H. (2012). vegan. Community Ecology Package. R Package Version 2.5-6, 2(9), 263. Retrieved from https://cran.r-project.org/web/packages/vegan/vegan.pdf

Parc Naturel des Ballons des Vosges (2019). Avenir du Grand Tétras dans le massif des Vosges : questions sociales et écologiques. Note de cadrage du Conseil scientifique du PNR des Ballons des Vosges. Unpublished Report. 5 pp.

Pegard, A., Miquel, C., Valentini, A., Coissac, E., Bouvier, F., François, D., Taberlet, P., Engel, E., \& Pompanon, F. (2009). Universal DNA-based methods for assessing the diet of grazing livestock and wildlife from feces. Journal of Agricultural and Food Chemistry, 57(13), 57005706. https://doi.org/10.1021/jf803680c

Picozzi, N., Moss, R., \& Catt, D. C. (1996). Capercaillie habitat, diet and management in a Sitka spruce plantation in central Scotland. Forestry, 69(4), 373-388. https://doi.org/10.1093/forestry/69.4.373

Picozzi, N., Moss, R., \& Kortland, K. (1999). Diet and survival of capercaillie Tetrao urogallus chicks in Scotland. Wildlife Biology, 5(February), 11-23. https://doi.org/10.2981/wlb.1999.004 
Price, E. R., Brun, A., Caviedes-Vidal, E., \& Karasov, W. H. (2015) Digestive adaptations of aerial lifestyles. Physiology, 30(1), 69-78. https://doi.org/10.1152/physiol.00020.2014

Quéméré, E., Hibert, F., Miquel, C., Lhuillier, E., Rasolondraibe, E., Champeau, J., Rabarivola, C., Nusbaumer, L., Chatelain, C., Gautier, L., Ranirison, P., Crouau-Roy, B., Taberlet, P., \& Chikhi, L. (2013). A DNA Metabarcoding Study of a Primate Dietary Diversity and Plasticity across Its Entire Fragmented Range. PLoS One, 8(3), e58971. https://doi.org/10.1371/journal.pone.0058971

Quevedo, M., Bañuelos, M. J., Sáez, O., \& Obeso, J. R. (2006). Habitat selection by Cantabrian capercaillie Tetrao urogallus cantabricus at the edge of the species' distribution. Wildlife Biology, 12(3), 267-276.

Rayé, G., Miquel, C., Coissac, E., Redjadj, C., Loison, A., \& Taberlet, P. (2011). New insights on diet variability revealed by DNA barcoding and high-throughput pyrosequencing: chamois diet in autumn as a case study. Ecological Research, 26(2), 265-276. https://doi. org/10.1007/s11284-010-0780-5

Rodrìguez, A. E., \& Obeso, J. R. (2000). Diet of the Cantabrian Capercaillie: geographic variation and energetic content. Ardeola, 47(1), 77-83.

Rolstad, J. (1988). Use of aspen Populus tremula by Capercaillie Tetrao urogallus in southeastern Norway. Ornis Fennica, 65(2), 65-68.

Sachot, S., Perrin, N., \& Neet, C. (2006). Viability and management of an endangered Capercaillie (Tetrao urogallus) metapopulation in the Jura Mountains, western Switzerland. Biodiversity and Conservation, 15(6), 2017-2032. https://doi.org/10.1007/s10531-005-0771-y

Saniga, M. (1998). Diet of the capercaillie (Tetrao urogallus) in a CentralEuropean mixed spruce-beech-fir and mountain spruce forest. Folia Zoologica, 47(2), 115-124.

Schnell, I. B. B., Bohmann, K., \& Gilbert, M. T. P. (2015). Tag jumps illuminated - reducing sequence-to-sample misidentifications in metabarcoding studies. Molecular Ecology Resources, 15(6), 12891303. https://doi.org/10.1111/1755-0998.12402

Sedinger, J. S. (1997). Adaptations to and consequences of an herbivorous diet in grouse and waterfowl. Condor, 99(2), 314-326. https:// doi.org/10.2307/1369937

Segelbacher, G., Hoglund, J., Storch, I., Höglund, J., \& Storch, I. (2003). From connectivity to isolation: Genetic consequences of population fragmentation in capercaillie across Europe. Molecular Ecology, 12(7), 1773-1780. https://doi.org/10.1046/j.1365-294X.2003.01873.x

Selas, V. (2000). Population dynamics of capercaillie Tetrao urogallus in relation to bilberry Vaccinium myrtillus production in southern Norway. Wildlife Biology, 6(1), 1-11.

Shepard, R. N. (1962a). The analysis of proximities: Multidimensional scaling with an unknown distance function. I. Psychometrika, 27(2), 125-140. https://doi.org/10.1007/BF02289630

Shepard, R. N. (1962b). The analysis of proximities: Multidimensional scaling with an unknown distance function. II. Psychometrika, 27(3), 219-246. https://doi.org/10.1007/BF02289621

Sheppard, S. K., \& Harwood, J. D. (2005). Advances in molecular ecology: Tracking trophic links through predator-prey food-webs. Functional Ecology, 19, 751-762. https://doi. org/10.1111/j.1365-2435.2005.01041.x

Shrestha, R., \& Wegge, P. (2006). Determining the composition of herbivore diets in the trans-Himalayan rangelands: A comparison of field methods. Rangeland Ecology and Management, 59(5), 512-518. https://doi.org/10.2111/06-022R2.1

Soininen, E. M., Gauthier, G., Bilodeau, F., Berteaux, D., Gielly, L., Taberlet, P., Gussarova, G., Bellemain, E., Hassel, K., Stenøien, H. K., Epp, L., Schrøder-Nielsen, A., Brochmann, C., \& Yoccoz, N. G. (2015). Highly overlapping winter diet in two sympatric lemming species revealed by DNA metabarcoding. PLoS One, 10(1), 1-18. https://doi.org/10.1371/journal.pone.0115335

Soininen, E. M., Valentini, A., Coissac, E., Miquel, C., Gielly, L., Brochmann, C., Brysting, A. K., Sønstebø, J. H., Ims, R. A., Yoccoz,
N. G., \& Taberlet, P. (2009). Analysing diet of small herbivores: The efficiency of DNA barcoding coupled with high-throughput pyrosequencing for deciphering the composition of complex plant mixtures. Frontiers in Zoology, 6(1), 1-9. https://doi. org/10.1186/1742-9994-6-16

Sønstebø, J. H., Gielly, L., Brysting, A. K., Elven, R., Edwards, M., Haile, J., Willerslev, E., Coissac, E., Rioux, D., Sannier, J., Taberlet, P., \& Brochmann, C. (2010). Using next-generation sequencing for molecular reconstruction of past Arctic vegetation and climate. Molecular Ecology Resources, 10(6), 1009-1018. https://doi. org/10.1111/j.1755-0998.2010.02855.x

Srivathsan, A., Ang, A., Vogler, A. P., \& Meier, R. (2016). Fecal metagenomics for the simultaneous assessment of diet, parasites, and population genetics of an understudied primate. Frontiers in Zoology, 13(1), 1-13. https://doi.org/10.1186/s12983-016-0150-4

Storch, I. (1993). Habitat selection by capercaillie in summer and autumn: Is bilberry important? Oecologia, 95(2), 257-265. https://doi. org/10.1007/BF00323498

Storch, I. (2000). Grouse: status survey and conservation plan 2000-2004. Retrieved from http://www.sidalc.net/cgi-bin/wxis.exe/?lsisS cript $=$ orton.$x i s \&$ method $=$ post $\&$ formato $=2 \&$ cantidad $=1 \&$ expre sion $=m f n=074553$

Storch, I. (2007). Conservation status of grouse worldwide: An update. Wildlife Biology, 13(Suppl. 1), 5-12.

Suter, W., Graf, R. F., \& Hess, R. (2002). Capercaillie (Tetrao urogallus) and avian biodiversity: Testing the umbrella-species concept. Conservation Biology, 16(3), 778-788. https://doi. org/10.1046/j.1523-1739.2002.01129.x

Taberlet, P., Coissac, E., Pompanon, F., Gielly, L., Miquel, C., Valentini, A., Vermat, T., Corthier, G., Brochmann, C., \& Willerslev, E. (2007). Power and limitations of the chloroplast trnL (UAA) intron for plant DNA barcoding. Nucleic Acids Research, 35(3), https://doi. org/10.1093/nar/gkl938

ter Schure, A. T. M., Pillai, A. A. S., Thorbek, L., Bhavani Shankar, M., Puri, R., Ravikanth, G., de Boer, H. J., \& Boessenkool, S. (2020). eDNA metabarcoding reveals dietary niche overlap among herbivores in an Indian wildlife sanctuary. Environmental DNA. https://onlinelibr ary.wiley.com/doi/abs/10.1002/edn3.168

Thiel, D., Jenni-Eiermann, S., Braunisch, V., Palme, R., \& Jenni, L. (2008). Ski tourism affects habitat use and evokes a physiological stress response in capercaillie Tetrao urogallus: A new methodological approach. Journal of Applied Ecology, 45(3), 845-853. https://doi. org/10.1111/j.1365-2664.2008.01465.x

Valentini, A., Miquel, C., Nawaz, M. A., Bellemain, E., Coissac, E., Pompanon, F., \& Taberlet, P. (2009a). New perspectives in diet analysis based on DNA barcoding and parallel pyrosequencing: The trnL approach. Molecular Ecology Resources, 9(1), 51-60. https://doi. org/10.1111/j.1755-0998.2008.02352.x

Valentini, A., Pompanon, F., \& Taberlet, P. (2009b). DNA barcoding for ecologists. Trends in Ecology and Evolution, 24(2), 110-117. https:// doi.org/10.1016/j.tree.2008.09.011

Vallant, S., Niederstätter, H., Berger, B., Lentner, R., \& Parson, W. (2018). Increased DNA typing success for feces and feathers of capercaillie (Tetrao urogallus) and black grouse (Tetrao tetrix). Ecology and Evolution, 1, 1-11. https://doi.org/10.1002/ece3.3951

Wegge, P., \& Kastdalen, L. (2008). Habitat and diet of young grouse broods: Resource partitioning between Capercaillie (Tetrao urogallus) and Black Grouse (Tetrao tetrix) in boreal forests. Journal of Ornithology, 149(2), 237-244. https://doi.org/10.1007/s1033 6-007-0265-7

Willerslev, E., Davison, J., Moora, M., Zobel, M., Coissac, E., Edwards, M. E., Lorenzen, E. D., Vestergård, M., Gussarova, G., Haile, J., Craine, J., Gielly, L., Boessenkool, S., Epp, L. S., Pearman, P. B., Cheddadi, R., Murray, D., Bråthen, K. A., Yoccoz, N., ... Taberlet, P. (2014). 
Fifty thousand years of Arctic vegetation and megafaunal diet. Nature, 506(7486), 47-51. https://doi.org/10.1038/nature12921

\section{SUPPORTING INFORMATION}

Additional supporting information may be found online in the Supporting Information section.
How to cite this article: Chua, P. Y. S., Lammers, Y., Menoni, E., Ekrem, T., Bohmann, K., Boessenkool, S., \& Alsos, I. G. (2021). Molecular dietary analyses of western capercaillies (Tetrao urogallus) reveal a diverse diet. Environmental DNA, 00, 1-16. https://doi.org/10.1002/edn3.237 